\title{
Pregnancy in patients presenting with hyperprolactinaemia
}

\author{
M O THORNER, C R W EDWARDS, M CHARLESWORTH, J E DACIE, P J A MOULT, \\ L H REES, A E JONES, G M BESSER
}

British Medical fournal, 1979, 2, 771-774

\section{Summary and conclusions}

Ninety-two pregnancies occurred in 76 hyperprolactinaemic patients treated with bromocriptine. Half conceived within three months of attempted conception. There was no evidence of an increased rate of spontaneous abortion, fetal abnormality, or multiple pregnancy; the three twin pregnancies occurred in women who were additionally treated with clomiphene and human chorionic gonadotrophin. Thirty-one patients had radiological evidence of a pituitary tumour; 14 with major radiograph changes in the pituitary fossa or serum prolactin concentrations greater than $100 \mathrm{ng} / \mathrm{ml}$ received pituitary irradiation before conception. None of the latter showed evidence of enlargement of the tumour during pregnancy. In contrast two of the four patients with similar tumours but who were not irradiated developed visual field defects, one with gross destruction of the pituitary fossa. Prophylactic treatment to limit subsequent tumour expansion during pregnancy in

Departments of Endocrinology, Chemical Endocrinology, Diagnostic Radiology, and Radiotherapy, St Bartholomew's Hospital, London EC1A 7BE

M O THORNER, MB, MRCP, lecturer

C R W EDWARDS, MD, FRCP, senior lecturer

M CHARLESWORTH, MB, FRCR, consultant radiologist

J E DACIE, MB, FRCR, consultant radiologist

P J A MOULT, MD, MRCP, MRC training fellow

L H REES, MD, FRCP, professor of chemical endocrinology

A E JONES, MD, FRCP, professor of radiotherapy

G M BESSER, MD, FRCP, professor of endocrinology patients with prolactinomas is indicated, and pituitary irradiation before conception appears to be a safe and effective method to achieve this goal.

\section{Introduction}

Raised prolactin concentrations in women are commonly associated with infertility. ${ }^{1-3}$ Early small series showed that bromocriptine lowers prolactin concentrations and restores gonadal function, irrespective of whether an obvious pituitary tumour is present. ${ }^{13} 4 \mathrm{~A}$ major management problem, however, is the risk of expansion of the tumour from rising oestrogen concentrations during pregnancy. Despite discussion on whether any active steps are required to avoid this, the question is unresolved. ${ }^{3-5}$ We therefore present our experience with 92 pregnancies in 76 bromocriptine-treated hyperprolactinaemic women, of whom 31 had radiological evidence to suggest the presence of a pituitary tumour. The efficacy of fertility promotion with bromocriptine is confirmed in this large group, but so is the risk in patients with obvious prolactinomas; however, our results suggest that radiotherapy is a safe and effective method of avoiding this complication.

\section{Patients}

Between 1969 and 197876 patients were first seen at St Bartholomew's Hospital (table I for clinical details). One patient was referred to us from abroad after developing visual field defects during a pregnancy that occurred during bromocriptine treatment, and some details of this patient were presented by Bergh et al. ${ }^{5}$ Ten pregnancies in nine of the present series of patients were reported in our earlier paper. ${ }^{4}$ No patient had evidence of hepatic or renal disease and none had taken any drugs likely to raise prolactin concentrations, except for oral contraceptives that had been taken at some time by most patients but had been discontinued at least six months before. Figure 1 shows serum prolactin concentrations before treatment. 
TABLE I-Summary of clinical data on presentation in 76 women who conceived while taking bromocriptine

\begin{tabular}{ccccc}
\hline $\begin{array}{c}\text { Pituitary fossa } \\
\text { grade }\end{array}$ & $\begin{array}{c}\text { Number of } \\
\text { patients }\end{array}$ & Amenorrhoea & $\begin{array}{c}\text { Irregular } \\
\text { menses }\end{array}$ & Regular menses \\
\hline B0 & 8 & 1 & 3 & 4 \\
B1 & 23 & 8 & 11 & 4 \\
B2 & 14 & 3 & 5 & 6 \\
B3 & 23 & 13 & 6 & 4 \\
B4 & 5 & 4 & 1 & 0 \\
B5 & 3 & 3 & 0 & 18 \\
\hline Total & 76 & 32 & 26 & \\
\hline
\end{tabular}

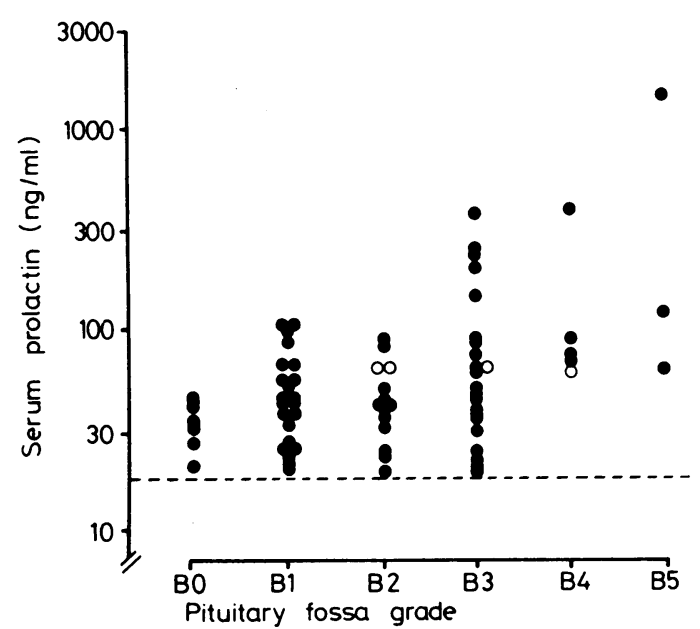

FIG 1-Serum prolactin concentration in patients grouped according to grade of radiological abnormality of pituitary fossa. Dotted line represents upper limit of normal range. Open symbols are minimum values obtained from undiluted sera.

TABLE II-Pituitary fossa classification from skull radiographs (modified from Doyle and McLachlan ${ }^{10}$ )

\begin{tabular}{|c|c|c|c|}
\hline Grade & Lateral view & Posteroanterior view & Interpretation \\
\hline Bo & Single contour & Flat floor: no blistering & Normal \\
\hline B1 & $\begin{array}{l}\text { Less then } 1 \mathrm{~mm} \text { difference } \\
\text { between contours }\end{array}$ & $\begin{array}{l}\text { Minimal slope: less than } \\
1 \mathrm{~mm} \text { dip }\end{array}$ & $\begin{array}{l}\text { Probably } \\
\text { normal }\end{array}$ \\
\hline B2 & $\begin{array}{l}\text { 1-3 mm difference } \\
\text { between contours; } \\
\text { less than } 3 \mathrm{~mm} \text { blister }\end{array}$ & $1-3 \mathrm{~mm}$ dip & $\begin{array}{l}\text { Possibly } \\
\text { abnormal }\end{array}$ \\
\hline $\begin{array}{l}\text { B3 } \\
\text { B4 } \\
\text { B5 }\end{array}$ & $\begin{array}{l}\text { Over } 3 \mathrm{~mm} \text { blister } \\
\text { Double contour throughout } \\
\text { Both sides of fossa expanded }\end{array}$ & $\begin{array}{l}\text { Asymmetry over } 3 \mathrm{~mm} \\
\text { Asymmetry over } 3 \mathrm{~mm} \\
\text { ll directions (ballooned fossa) }\end{array}$ & $\begin{array}{l}\text { Abnormal } \\
\text { Abnormal } \\
\text { Abnormal }\end{array}$ \\
\hline
\end{tabular}

If the cortex is breached then the fossa is classified as above but $\mathrm{E}$ is added-for example B4E. Grades B3 to B5 are regarded as "suspected pituitary tumours" for
the purpose of this paper.

Infertility had been present from three months to 11 years in 54 patients; in 52 for more than one year. Twenty-two patients had not attempted to conceive before they had been treated with bromocriptine, but rather presented with menstrual disturbances.

\section{Clinical management}

All patients were carefully assessed for evidence of pituitary tumours, and central visual fields were plotted. Our level of suspicion of a tumour was high as microadenomas that secrete prolactin may be peripheral and small $^{6} 7$; often the only evidence of their presence is slight asymmetry of the pituitary fossa on skull radiographs, giving the appearance of a double floor in the lateral skull film or a slight dip to the floor on the posteroanterior view. ${ }^{i-10}$

Skull radiographs-Standard lateral and posteroanterior skull radiographs were classified depending on the size and symmetry of the fossa, and the presence or absence of erosion. The plain films were supplemented by tomography if the degree of abnormality was not clear. When we first started to use bromocriptine in $1971^{11}$ the subthe radiological changes now known to indicate the presence of a pituitary microadenoma were less clear than at present, and therefore we have revised our original interpretation of the presenting radiographs in some patients. Our grading of the fossa is based on that of Doyle and McLachlan, ${ }^{10}$ as shown in table II, modified so that greater degree of abnormality is given higher values. We use the term "suspected pituitary tumour" to indicate patients with fossa grades of B3-B5 (table II). In patients thought likely to need radiotherapy (see below) pneumoencephalography was performed to check for the presence of a suprasellar extension to any tumour, to aid in planning irradiation, and to exclude a partially empty fossa. The one patient with a suprasellar extension had this removed by a transfrontal approach before irradiation.

\section{Methods}

Standard dynamic pituitary function tests for pituitary hormone reserve were performed, ${ }^{12}{ }^{13}$ and the data are available from the authors.

Assays-Serum prolactin concentrations were measured by radioimmunoassay. ${ }^{14}$ The normal range in women for prolactin, is 4 to $18 \mathrm{ng} / \mathrm{ml}$ (MRC standard $71 / 222$ ).

Bromocriptine treatment was started with a dose of 1.25 or $2.5 \mathrm{mg}$ on retiring and slowly increased to between 5 and $15 \mathrm{mg}$ a day. The usual dose ( 46 patients) was $7.5 \mathrm{mg}$ a day, and all tablets were taken with food. All patients were advised to take mechanical contraceptive precautions after starting treatment and to wait until at least three regular monthly menstrual cycles had occurred before trying to conceive or until three cycles after the end of radiotherapy, if performed. After attempting to conceive, the patients were advised to stop taking bromocriptine as soon as the first period had been missed by 48 hours. One hyperprolactinaemic patient's husband had hypogonadotrophic hypogonadism that was treated with menopausal and chorionic gonadotrophins to promote spermatogenesis. All patients with suspected pituitary tumours had central visual field plotting each month throughout pregnancy.

Radiotherapy was given to those patients with suspected pituitary tumours who had B4 or B5 pituitary fossa grades unless they showed an empty fossa or suprasellar extension and to patients with B3 fossae if the mean of three prolactin values on presentation was over $100 \mathrm{ng} / \mathrm{ml}$. Of the 31 patients with suspected pituitary tumours, 13 did not fulfil the criteria for radiotherapy. Fourteen were given radiotherapy, and a further four fulfilled the criteria but were not treated for the following reasons: one (B5) became pregnant unexpectedly despite taking mechanical contraceptive precautions; one (fossa B4 at conception) was referred after she had developed visual field defects during pregnancy; and two early patients with B3 fossae had prolactin values of over $100 \mathrm{ng} / \mathrm{ml}$ and would now be irradiated. Radiotherapy was given as a planned procedure to deliver a lesion dose of 4500 rads in 25 fractions in 35 days, using a $4 \mathrm{MeV}$ linear accelerator and a three-field technique, individually planned with full isodosimetry to localise treatment to the pituitary, and irradiation of the hypothalamus, brain stem, and temporal lobes was kept to a minimum.

\section{Results}

BROMOCRIPTINE TREATMENT, MENSES, CONCEPTION, AND DELIVERY

Bromocriptine lowered prolactin values in all 76 patients. On treatment the values were normal in all except six in whom they varied between 27 and $50 \mathrm{ng} / \mathrm{ml}$. Despite these values the patients taking bromocriptine ovulated and were fertile, whereas they had been hypogonadal before. Normal menstrual cycles were restored to 54 women after treatment lasting from three weeks to 10 months. In one patient periods returned but remained irregular. Galactorrhoea ceased in most. Eighteen patients, though infertile, had regular periods before treatment, and menstruation remained regular while taking bromocriptine. Thirty-nine of 79 deliberate conceptions occurred within three months of attempting conception, the remainder taking up to 30 months. Clomiphene was added in 16 patients who had not conceived by three months, but these patients had been resistant to clomiphene before taking bromocriptine, and there were three twin pregnancies in this group. Eight women have had two bromocriptine pregnancies and four women three. Thirteen patients conceived despite taking mechanical contraceptive precautions. Sixty-five babies have been born at the time of writing, and none has major congenital malformations. There were 17 spontaneous abortions, one ectopic pregnancy, one intrauterine death, and two therapeutic terminations. 
The overall rate of spontaneous fetal loss was $21 \%$. Three of the 17 spontaneous abortions occurred at less than eight weeks' gestation.

The course of the pregnancies was uneventful in all but six patients. One had a pronounced asymmetric fossa and was started on bromocriptine when abroad without pretreatment. She ignored advice against becoming pregnant until the tumour had been treated. At 30 weeks she developed bitemporal hemianopia. Her fossa showed gross destruction (B5E); before pregnancy it had shown just grade B4 asymmetry (fig 2). With the development of the field defects she

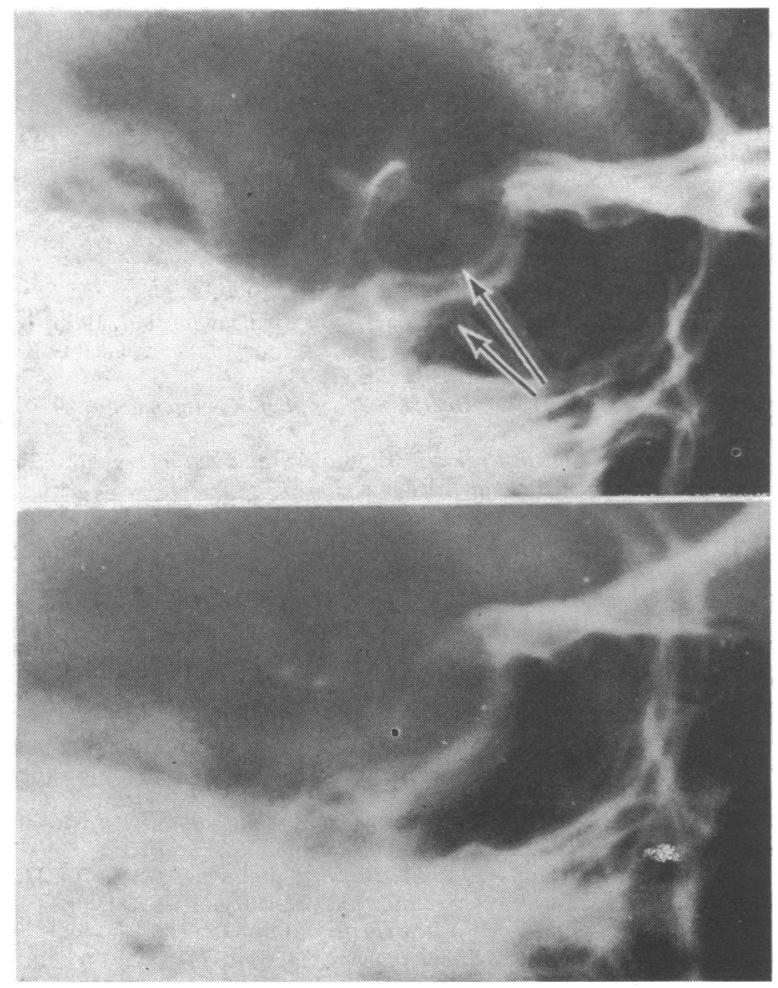

FIG 2-Pituitary fossa radiographs in a patient whose prolactinoma enlarged in pregnancy. Top: six months before conception there is asymmetry of pituitary fossa with a double floor (B4 arrowed). Bottom: at $\mathbf{3 0}$ weeks gestation fossa has been destroyed by expanding tumour (B5E).

was restarted on bromocriptine, $15 \mathrm{mg}$ a day, and the visual fields improved, although they were not restored to normal. She delivered at term a normal baby. After delivery her visual fields returned to normal, but computerised axial tomograms showed a suprasellar extension. This patient is referred to by Bergh et al. ${ }^{5}$ Another patient had a large pituitary tumour (B5E) with a small suprasellar extension, and for this reason pregnancy was not desired. She conceived while taking bromocriptine, despite an intrauterine contraceptive device, and by five weeks bitemporal field defects were present that disappeared after a spontaneous abortion at six weeks, when bromocriptine was restarted. Visual fields showed no changes during the other pregnancies, and repeat skull radiographs after delivery showed no alteration in fossa configuration.

\section{Discussion}

Hyperprolactinaemia is a common cause of female infertility and was difficult to treat until the introduction of bromocriptine. Bromocriptine is simple and effective to use, and there is no evidence of teratogenicity associated with the births recorded. ${ }^{15}$ Our results extend and confirm this experience. The $21 \%$ rate of spontaneous fetal loss is significantly greater than that reported in a normal population, ${ }^{16}$ but compares favourably with the rate in patients treated with menopausal gonadotrophin. ${ }^{17}$

Most now agree that patients with hyperprolactinaemia who are not hypothyroid or taking any drug likely to raise prolactin values harbour either a frank pituitary tumour or a micro- adenoma-and this may be present even when the skull radiographs show only minor changes, including small blisters or minor asymmetry of the fossa floor previously thought to be normal. ${ }^{6} \rightarrow$ The major concern with using bromocriptine to induce fertility in hyperprolactinaemic women is the risk of expansion of a pituitary tumour during pregnancy leading to visual field defects. The incidence of tumour expansion during pregnancy without prior treatment to restrict tumour growth may be as high as $35_{\%}^{\circ}$ but in the group with microadenomas is about $5 \% .^{518}$

To evaluate our experience of this clinical condition we have found it helpful to grade the pituitary fossa radiographs to aid objective assessment. Our classification is more objective in its description of the fossa size than that proposed by Vezina and Sutton, ${ }^{7}$ which rather places greater emphasis on the presence or absence of bone erosion. Our classification incorporates the presence or absence of erosion as a separate factor without biasing the grading, which is dependent on the actual pituitary enlargement. A uniform and clearly defined grading of the radiological appearances of the pituitary fossa would add greatly to the value of comparisons between patient groups studied at different centres.

As with the normal pituitary gland, tumours in the region of the fossa appear to increase in size during pregnancy, apparently under the stimulus of the rising oestrogen concentrations. Since the first description in $1908^{19}$ we have traced 32 other reports of visual field defects developing during pregnancy in women with tumours around the pituitary fossa region, and we know of other unreported cases. Twenty-nine reported women appeared to have pituitary tumours at the time the visual disturbance occurred; three had a meningioma or a craniopharyngioma. Visual field defects have occurred as early as the first month, after which the incidence is fairly uniform until the seventh month, the time most presented. In eight patients who developed visual field defects during more than one consecutive pregnancy the complication was worse with each pregnancy. In general, the visual symptoms persisted or worsened through the pregnancy and then improved after delivery. In 10 of the 29 patients there were residual visual deficits after delivery. Other evidence associated with swelling of the tumours has been encountered-such as headaches, vomiting, symptoms of raised intracranial pressure or diabetes insipidus, or changes in the fossa radiograph suggestive of pituitary enlargement.

From limited experience some have recommended that patients with pituitary tumours should undergo treatment to prevent rapid tumour growth before embarking on pregnancy. ${ }^{34620}$ The treatments advised include external irradiation, trans-sphenoidal surgery, or local irradiation with ${ }^{90}$ yttrium. An alternative approach ${ }^{5}$ suggested that the incidence of complications from tumour expansion is sufficiently low for an anticipatory policy to be followed. Evidence of tumour expansion occurred, however, in four of 14 patients $(29 \%)$ treated in this way, ${ }^{5}$ an incidence which we believe is unacceptably high, especially since permanent visual impairment may result. In our own series of 14 patients with pituitary tumours who received irradiation no patient developed field defects, headaches, radiographic changes, or any symptoms suggestive of pituitary enlargement during pregnancy. By contrast, field defects or fossa destruction occurred in the two patients with tumours who, despite clearly abnormal fossae (B4), received no irradiation since pregnancy had not been planned. Nevertheless, insufficient numbers of patients with tumours have been irradiated before conception to be certain that this treatment prevents the complication, and the question would be answered definitively only by a controlled trial comparing radiotherapy with no treatment. Nevertheless, the data suggest that irradiation is likely to prevent growth of the tumour during or after pregnancy. The only patient who had visual problems during pregnancy despite irradiation already had a recorded suprasellar extension before pregnancy. ${ }^{21}$

Against this possible benefit the possible complications of 
treatment must be considered. With careful planning with full isodosimetry for each patient, the use of an $x$-ray treatment simulator, and care in the execution of the irradiation-using a linear accelerator, limiting the modal dose to 4500 rads in five weeks, and delivering the radiation in daily fractions of less than 200 rads-the pituitary can be irradiated safely while sparing the neighbouring vital structures. Neural damage associated with external irradiation has in this dose range been reported only in patients exposed to fractions of more than 200 rads. Such complications have not been seen during follow-up of this form of treatment for pituitary tumours (delivering daily dose fractions of not more than 180 rads) in over 200 patients treated in our hospital, some of whom were irradiated nearly 20 years ago.

Whenever tissues receive therapeutic doses of irradiation there is always a theoretical possibility of late carcinogenesis, and we have considered this. Radiation-induced neoplasms have occasionally been reported after pituitary irradiation, but these have usually followed very high dosage or repeated courses. ${ }^{22}$ The volume of connective tissue irradiated in our technique is too small to allow extrapolation from the results of other clinical studies of carcinogenesis from external irradiation, such as those of ankylosing spondylitis. We consider that the risk of late carcinogenesis is slight compared with the substantial risk of visual deterioration during pregnancy in non-irradiated patients with tumours. Nevertheless, as the latent period for late carcinogenesis is related inversely to the evocative dose, long periods of observation of, perhaps, 30-50 years, of sufficient numbers of patients will be necessary before the true risk can be calculated.

We consider that on the present evidence external pituitary irradiation can be safe and should be given to women with clear evidence of a pituitary tumour and who wish to become pregnant to prevent pituitary tumour enlargement. For these reasons we now recommend pituitary irradiation in all patients with the most severely affected fossa abnormalities-B4 or 5-provided there is no suprasellar extension or an "empty fossa"; in addition we favour this treatment in patients whose fossae merely show the more minor B3 change if their average serum prolactin concentration is clearly in the tumour range (greater than $100 \mathrm{ng} / \mathrm{ml}$ ), although the risk in untreated patients in this group is probably less-more experience is required.
Whether alternative ablative treatments are used instead of external irradiation will clearly depend in part on the facilities and skill available in each centre, but also on the risks and incidence of hypopituitarism and recurrence associated with them.

We are grateful for support from the Joint Research Board, St Bartholomew's Hospital, the Peel Medical Trust, and the MRC PJAM is in receipt of an MRC training fellowship. Correspondence to Professor G M Besser.

\section{References}

1 Thorner, M O, and Besser, G M, Acta Endocrinologica, 1978, suppl 216, 88,131 .

${ }^{2}$ Kleinberg, D L, Noel, G L, and Frantz, A G, New England fournal of Medicine, 1977, 296, 589.

${ }^{3}$ Franks, S, et al, British fournal of Obstetrics and Gynaecology, 1977, 84, 241.

4 Thorner, M O, et al, British Medical fournal, 1975, 4, 694.

${ }^{5}$ Bergh, T, Nillius, S J, and Wide, L, British Medical fournal, 1978, 1, 875. ${ }^{6}$ Hardy, J, in Diagnosis and Management of Pituitary Tumors, ed P O Kohler and G T Ross. Amsterdam, Elsevier, 1973.

'Vezina, J, and Sutton, T L, American fournal of Roentgenology, 1974, 120, 46.

${ }^{8}$ Vezina, J L, in Progress in Prolactin Physiology and Pathology, ed C Robyn and M Harter. Amsterdam, Elsevier, 1978.

${ }^{9}$ Geehr, R B, et al, American fournal of Roentgenology, 1978, 130, 105.

10 Doyle, F, and McLachlan, M, Clinics in Endocrinology and Metabolism, 1977, 6(1), 53.

11 Besser, G M, et al, British Medical fournal, 1972, 3, 669.

12 Greenwood, F C, Landon, J, and Stamp, T C B, Fournal of Clinical Investigation, 1966, 45, 429.

${ }_{13}$ Mortimer, C H, et al, British Medical fournal, 1973, 4, 73.

14 McNeilly, A S, Proceedings of the Royal Society of Medicine, 1973, 66, 863.

${ }^{15}$ Griffith, R W, Turkalj, I, and Braun, P, British fournal of Clinical Pharmacology, 1978, 5, 227.

${ }^{16}$ German Research Council: Schwangerschaftsverlauf und Kindesentwicklung, Boppard, Harold Boldt Verlag, 1977.

17 Thompson, I E, and Hansen, L M, Fertility and Sterility, 1970, 21, 844.

${ }_{18}$ Gemzell, C, and Wang, C F, Fertility and Sterility, 1979, 31, 363.

19 Reuss, A, Wiener Klinische Wochenschrift, 1908, 31, 1116.

20 Child, D F, et al, British Medical fournal, 1975, 4, 87.

${ }^{21}$ Lamberts, S W J, et al, fournal of Clinical Endocrinology and Metabolism, $1977,44,180$

22 Waltz, T A, and Brownell, B, fournal of Neurosurgery, 1966, 24, 901.

(Accepted 2 August 1979)
There is some evidence that car occupants wearing seat belts can receive injuries to the neck, but in almost all reports the injuries are minor. These injuries arise from flexion, and although they may cause pain and stiffness, they generally resolve themselves without active treatment. Serious cervical injuries to occupants wearing seat belts have occurred, but in all cases where sufficient detailed information is available the head has apparently contacted some part of the car interior despite using a seat belt. ${ }^{1} \mathrm{~A}$ direct blow on the head is probably important in inducing those neck injuries. ${ }^{2}$ Reports of specific neck injuries caused by direct contact with the seat belt are extremely rare for three-point belts, and the injuries are minor. Probably, in a collision when the occupant moves forward under the influence of the crash decelerations the belt moves down from the neck to the clavicle before the loads in the belt build up to injurious levels.

In the early days of seat belts some people advocated single diagonal belts. Serious neck injuries and one decapitation with those belts have resulted from substantial rotation of the car with the door opening and the ejection of the occupant being prevented by the diagonal belt. ${ }^{3}$ This does not arise with a three-point belt because of the restraint applied by the lap section across the pelvis. In normal use there is an obvious problem of comfort in some cars, especially for people of small stature. The regulations give considerable latitude on the permitted position of the upper mounting point, and some manufacturers, particularly in countries where the fitting of seat belts is not yet compulsory, such as Italy, go to the extremes of the permissible range for the mounting point. As an individual all you can do is to complain to the manufacturer and avoid his products in the future. ' Gogler, $\mathrm{H}$, et al, Injury, 1979, 10, 196.
Mackay, G M, et al, 2nd International Conference, International Research Com-
mittee on the Biokinetics of Impact, $\mathrm{p} 20.1975$.
s Saldeen, T, fournal of Trauma, $1967,7,856$.

The local pathology laboratory have now installed an autoanalyser, and we are getting serum urate, urea, and creatinine estimations on all our patients with Down's syndrome and turning up several with hyperuricaemia, some of whom are also showing raised urea or creatinine, or both. Should patients with this finding be treated and, if so, with what?

Moderate hyperuricaemia is not uncommon in Down's syndrome. The relationship, if any, to the chromosomal abnormality is uncertain, although it should be remembered that there is an increased incidence of leukaemia in patients with Down's syndrome. I think that such hyperuricaemia should not be treated unless it is associated with acute gouty arthritis, when that disorder should be treated on its own merits. Similarly, there is no indication to treat raised blood urea or creatinine concentrations as such. 